\title{
Factors associated with Hospitalization among COVID-19 Home Quarantine Patients in Melaka Tengah District, Melaka, Malaysia
}

Syafiq, S.S. ${ }^{1,2} *$, J. Mohd Ridzuan ${ }^{1}$, Noor Aizam M.S. ${ }^{1}$, Kathy Lim Yeen Luan ${ }^{1,2}$, Ammar Hamzah $^{1,2}$, Muhammad Khairulahnaf Yusof ${ }^{1,2}$, Nur Hazifah Z. ${ }^{1,2}$ Nur Farhana Hamzah ${ }^{3}$

\section{Abstract}

Background: COVID-19 is an emerging new disease, recognized in late 2019, has since caused public health pandemic worldwide. Since the establishment of the COVID-19 Assessment Centre (CAC), cases were staged in terms of the severity. The mild cases were allowed for home quarantine and the severe cases were hospitalized. This study will assist healthcare providers to identify the high-risk patients and anticipate proactively, reducing morbidity and mortality. The study aimed to determine the incidence rate of hospitalization among home quarantined patients and its associated factors.

Methods: A case-control study design was conducted from 16th August until 30th September 2021 involving newly diagnosed COVID-19 patients under the CAC Melaka Tengah monitoring. A case was defined as home quarantined patient whom later required hospitalization, while a control was defined as home quarantined patient throughout the period. Analysis using Chi-square and Multiple Logistic Regression were done to determine the significant associated factors.

Results: There were 13,748 COVID-19 patients; with 8,237 were home quarantined and 82 required hospitalization later (1.0\%). A total of 164 patients were included (82 cases and 82 controls). Among the hospitalized, 30.5\% were aged 60 and above, $39.0 \%$ with comorbidity, $70.7 \%$ were symptomatic, and $40.2 \%$ were fully vaccinated. From the analysis, the only significant factor associated with hospitalization was age $>60$ years old $(\mathrm{p}<0.05)$.

Conclusion: There were home quarantined patients that required hospitalization later, especially the elderly patients. Thus, the CAC team should give priority for hospital admission to these cases instead of home quarantine order.

Keywords: COVID-19, Hospitalization, Associated factors, Case-control.
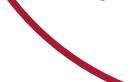

\footnotetext{
*Correspondence Email: syafiqsidqisaidi1985@gmail.com Melaka, Malaysia

${ }^{3}$ Poliklinik Fasya, Bukit Beruang, Melaka, Malaysia

Received: 15/12/2021
}

${ }^{I}$ Melaka Tengah District Health Office, Jalan Bukit Baru, 75150 Melaka, Malaysia

${ }^{2}$ Melaka Tengah COVID-19 Assessment Centre (CAC) Bukit Serindit, Jalan Taman Bandaran, Padang Semabok, 75400

Accepted: 26/12/2021 


\section{Introduction}

COVID-19 is an emerging new disease, recognized first in Wuhan, China, during the late 2019, and has since caused public health pandemic worldwide. The disease caused by the novel severe acute respiratory syndrome coronavirus-2 (SARS- CoV-2), and as $20^{\text {th }}$ November 2021, there were 255 million cases with over five million deaths worldwide (World Health Organization [WHO], 2021). The virus can spread from an infected person through respiratory droplets and aerosols.

Globally, majority of the cases were mild to moderate cases, as many as $80 \%$ of total cases had mild to moderate diseases, $15 \%$ having severe diseases, and 5\% became critically ill. The case fatality ratio by countries ranges between $1 \%$ and $12 \%$. In Malaysia, in year 2020, more than $90 \%$ of cases had mild diseases and low fatality rates, and these were contributed by the early compulsory hospitalization policy adopted by Malaysia Ministry of Health, regardless of disease stage upon diagnosis (Lim, B. et al., 2020). Early compulsory hospitalisation of cases allows close monitoring for deterioration and may prevent deaths. With regards to disease severity, similar findings were reported by a study in Melaka (Ahmad, B.Z. et al., 2021).

However, the increasing trend of new cases daily has stretched the ability to admit them to hospitals, and hence, the need of the COVID-19 Assessment Centre (CAC) establishment (Malaysia Ministry of Health [MOH], 2021). The objectives of the CAC are to identify and assess who are suitable for home quarantine, and monitor them with standardized tools. The CACs also will identify cases with disease progression and arrange for either quarantine centers- or hospital- referrals if required. Since then, cases were staged in terms of the severity. The mild cases were allowed for home quarantine, if they met these criteria; less than 60 years old, disease category 1-2, without or with stable comorbidities, suitable obstetric patients, together with suitable caregiver available and suitable home condition (MOH, 2021). The high-risk cases were hospitalized for further management. The CACs are regionally based, or according to each districts in each state. In Melaka state, currently, there are three CACs, one in each district; Melaka Tengah, Alor Gajah and Jasin districts.

COVID-19 is associated with significant morbidity and mortality. A study in Melaka showed that the number of COVID-19 deaths at homes or categorized as "brought-in-death" (BID) COVID-19 had increased up to $14.4 \%$, and majority of them failed to seek early treatment (Intan A.M.D. et al., 2021). However, only a subset of patients becomes critically ill. Even though the home quarantined COVID-19 patients are those with mild severity, they can sometimes require hospitalization as the disease progresses later on. Thus, the study on factors associated with hospitalization among home quarantined patients will assist healthcare providers to identify and anticipate proactively, in order reducing morbidity and mortality. From the data collected for this study, the incidence rate of hospitalization among home quarantined COVID-19 patients could be determined, as well as the study aimed to determine the significant factors associated with hospitalization.

\section{Methods}

A case-control study design was conducted from $16^{\text {th }}$ August until $30^{\text {th }}$ September 2021 involving newly diagnosed COVID-19 patients under the CAC Melaka Tengah monitoring. Since the establishment of the CAC Melaka Tengah on the $16^{\text {th }}$ August, all the patients' information; the socio-demographics, clinical data, disease category, vaccination status, triage disposition and latest status, were collected and kept in a computerized system. For this 
current study, the inclusion criteria were all COVID-19 patients under the CAC Melaka Tengah supervision with the Home Quarantine order from $16^{\text {th }}$ August $-30^{\text {th }}$ September 2021. Cases with hospitalization upon diagnosis were excluded. Cases with incomplete details were also excluded. A case was defined as home quarantined patient whom later required hospitalization, while a control was defined as home quarantined patient throughout the period. Sample size was 80 for each study group, calculated using the formula for independent case control study using qualitative variable, at $80 \%$ power and $\alpha=0.05$ (Charan, J. \& Biswas, T., 2013). During the study period, all Cases were selected and included, and the Controls were selected in a ratio of 1:1 by using Simple Random Sampling technique. Informed consent was obtained prior to the enrollment of patients into the study.

All data gathered were entered into an excel database, and analyzed using IBM Statistical Package for Social Sciences (SPSS) Statistics for Windows version 24. The dependent variable was hospitalization among the home quarantined patients, while the independent variables were the patients' socio-demographics, clinical data, disease category, and vaccination status. For bivariate analysis, analysis-using Chi-square or Fischer exact test, as appropriate, was done to determine the significant associated factors. As for the multivariate analysis, the Multiple Logistic Regression was done to determine the final significant associated factors.

\section{Results}

During the study period, there were 13,748 newly diagnosed COVID-19 patients; with 8,237 $(59.9 \%)$ were mild cases and allowed for home quarantined. A total of 164 patients were included in the study, as 82 patients represented the cases, and 82 patients represented the controls. The median (IQR) age for all studied patients was 33.0 (23.5) years old. Based on the Table 1, majority of the respondents came from the 30-39 years old age group (29.9\%). Female patients were slightly dominant $(53.7 \%)$. Majority of the patients were Malaysians $(86.6 \%)$ and Malays $(71.3 \%)$. Majority of the patients were unemployed (71.3\%). At the time of the study, only $34.8 \%$ of them were fully vaccinated with two doses. Most of the patients had no comorbidities $(75.6 \%)$ and were adult cases $(82.9 \%)$. Only $2.4 \%$ were pregnant ladies. In terms of the smoking habit, $94.5 \%$ were non-smokers. With regards to the clinical manifestations, $62.2 \%$ patients presented with symptoms.

From the data collected with regards to the total of the home quarantined patients, $82(1.0 \%)$ patients were later had been admitted to the hospitals, due to worsening disease condition. Among these hospitalized patients, 30.5\% were aged 60 years old and above, $39.0 \%$ of them with at least one comorbidity. Majority of the patients (70.7\%) were symptomatic, and $40.2 \%$ were fully vaccinated with two doses.

From the bivariate analysis (Table 1), age, race, occupation, comorbidities, and symptoms were significant associated factors with hospitalization, and hence, these variables were included in the multivariate analysis model. From the analysis, by using Simple Logistic Regression, all mentioned factors were significant, however, by using Multiple Logistic Regression, the only significant factor associated with hospitalization among the home quarantined COVID-19 patients was increasing age $(\mathrm{p}=0.005)$ (Table 2). 
Table 1: Distribution of the variables among the patients

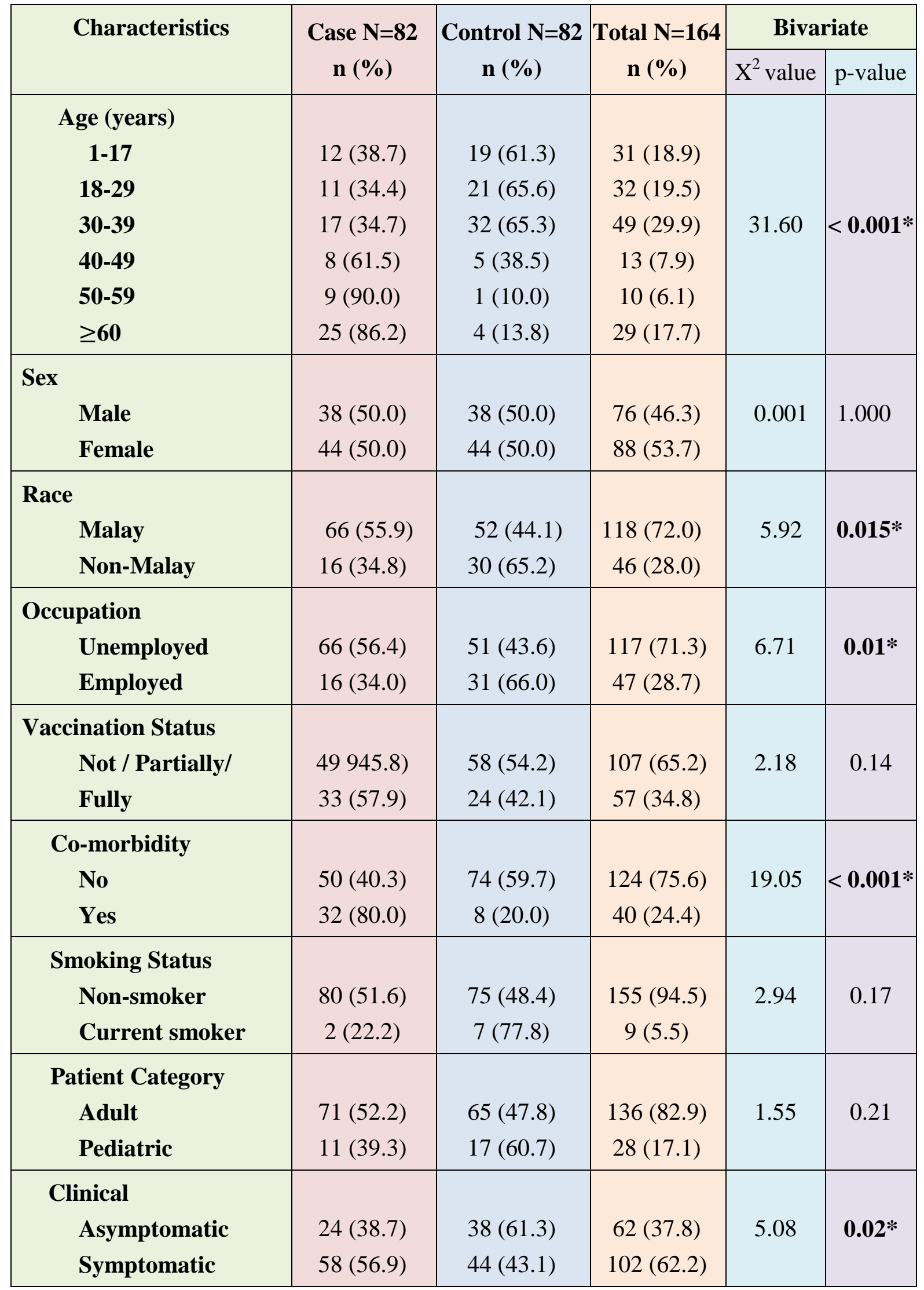

Notes: $\mathrm{X}^{2}$ value - Chi square value, ${ }^{*}$ p-value of $<0.05$ was significant 
Table 2: Multivariable analysis for significant associated factors with hospitalization among home quarantined patients $(\mathrm{N}=164)$

\begin{tabular}{|c|c|c|c|c|c|c|}
\hline \multirow[b]{2}{*}{ Parameter } & \multicolumn{3}{|c|}{ Simple Logistic Regression } & \multicolumn{3}{|c|}{ Multiple Logistic Regression } \\
\hline & Coefficient & $\begin{array}{l}\text { Crude OR } \\
(95 \% \text { CI })\end{array}$ & p-value & Coefficient & $\begin{array}{c}\text { Adjusted OR } \\
(95 \% \mathrm{CI})\end{array}$ & p-value \\
\hline Age (years) & & & & & & \\
\hline $1-17$ & & 1 & & & 1 & \\
\hline 18-29 & -0.19 & $\begin{array}{c}0.83(0.30 \\
2.32)\end{array}$ & 0.721 & -0.081 & $\begin{array}{c}0.92(0.26 \\
3.33)\end{array}$ & 0.902 \\
\hline 30-39 & -0.17 & $\begin{array}{c}0.84(0.33, \\
2.14)\end{array}$ & 0.716 & 0.071 & $\begin{array}{c}1.074(0.36 \\
3.17)\end{array}$ & 0.898 \\
\hline $40-49$ & 0.93 & $\begin{array}{c}2.53(0.67 \\
9.59)\end{array}$ & 0.171 & 1.09 & $\begin{array}{c}2.98(0.68 \\
13.13)\end{array}$ & 0.150 \\
\hline $50-59$ & 2.66 & $\begin{array}{c}14.25(1.60, \\
127.17)\end{array}$ & $0.017 *$ & 2.23 & $\begin{array}{c}9.28(0.97 \\
88.34)\end{array}$ & 0.053 \\
\hline$\geq 60$ & 2.29 & $\begin{array}{c}9.90(2.75 \\
35.56)\end{array}$ & $<0.001 *$ & 2.11 & $\begin{array}{l}8.28(1.88 \\
36.44)\end{array}$ & $0.005^{*}$ \\
\hline \begin{tabular}{|l} 
Race \\
Malay \\
Non-Malay
\end{tabular} & -0.87 & \begin{tabular}{|c}
1 \\
$0.42(0.21$ \\
$0.85)$ \\
\end{tabular} & $0.016 *$ & 0.58 & $\begin{array}{c}1 \\
1.79(0.57 \\
5.64) \\
\end{array}$ & 0.319 \\
\hline \begin{tabular}{|l} 
Occupation \\
Unemployed \\
Employed
\end{tabular} & -0.92 & \begin{tabular}{|c|}
1 \\
$0.40(0.20$ \\
$0.81)$ \\
\end{tabular} & $0.011 *$ & -.0 .064 & $\begin{array}{c}1 \\
0.94(0.34 \\
2.61) \\
\end{array}$ & 0.902 \\
\hline Co-morbidity & 1.78 & \begin{tabular}{|c}
1 \\
$5.92(2.52$ \\
$13.90)$ \\
\end{tabular} & $<0.001 *$ & 0.67 & $\begin{array}{c}1 \\
1.94(0.70 \\
5.44) \\
\end{array}$ & 0.205 \\
\hline $\begin{array}{l}\text { Clinical } \\
\text { Asymptomatic } \\
\text { Symptomatic }\end{array}$ & 0.74 & $\begin{array}{c}1 \\
2.09(1.10 \\
3.97)\end{array}$ & $0.025 *$ & 0.84 & $\begin{array}{c}1 \\
2.31(0.98 \\
5.43) \\
\end{array}$ & 0.05 \\
\hline
\end{tabular}

Notes: OR - odds ratio, ${ }^{*} \mathrm{p}$-value of $<0.05$ was significant

Discussion

This study finding showed that majority of the COVID-19 cases were mild cases, and this was similar finding worldwide and in Malaysia (Lim, B. et al., 2020). The median age of the studied patients was comparable with other studies across the states in this country (Ahmad, N., et al., 2021, Hasani, W.S. et al., 2021, \& Lim, B. et al., 2020). On the contrary, studies in New York, China, Korea and Singapore demonstrated a much older group of patients, between the age of 40 and 63 years old (Lim, B. et al., 2020). In terms of the comorbidities and clinical presentations, the finding was similar with other local studies (Ahmad, N., et al., 2021, Hasani, W.S. et al., 2021, \& Lim, B. et al., 2020). 
Initially, Malaysia opted for a compulsory hospitalization policy for all COVID-19 cases, upon diagnosis, regardless the disease category and clinical presentations. However, since the increasing number of cases from mid-to-end August 2021, the capabilities had stretched and only high-risk cases were given priority to be hospitalized. The incidence rate of hospitalization may vary globally, depending on each country own policy. Statistic had been shown that, in Malaysia, the number of cases being admitted to the hospitals had been reduced since the increasing number of fully vaccinated adult population in many states (COVIDNOW, 2021). However, the information on the incidence rate of hospitalization among the home quarantined patients is still lacking. Thus, the study finding gives early information on this, and it showed evidence that, there were still possibilities that the mild, home quarantined patients required hospitalization later during the quarantine period.

From the literature reviews, older age, male, comorbidities such as diabetes, hypertension, obesity, coronary artery disease and chronic kidney disease were significant factors being associated with hospitalization among COVID-19 patients (Gottlieb, M. et al., 2020, Ko, J.Y. et al., 2020, Mendy, A. et al., 2020, Petrilli, C.M. et al., 2020, \& Telle, K.E. et al., 2021). Age above 60 years old was significantly associated with hospitalization, with an odds ratio (OR) of $8.28(95 \% \mathrm{CI}=1.88$ to 36.44$)$. This study finding was consistent with prior literatures (Gottlieb, M. et al., 2020, Ko, J.Y. et al., 2020, Mendy, A. et al., 2020, Petrilli, C.M. et al., 2020, \& Telle, K.E. et al., 2021). Another study in Selangor, Malaysia, found that the proportion of COVID-19 patients who required intubation or mechanical ventilation increased with age (Hasani, W.S. et al., 2021). Even though all age groups are at risk of contracting COVID-19, elderly have significant risk of severe disease, possible because of their physiological changes, as the body strength and immune system reduces with ageing. Another explanation is that, elderly patients have more potential underlying health conditions, as this could further increase the risk of severe disease and hospitalization.

Trained and competent healthcare workers did the assessment of each of the COVID-19 patient presented to CACs. They will be assessed according to a guideline or criteria set by the Malaysia Ministry of Health. This study findings further supported and showed that the current management of our COVID-19 patients, especially with regards to elderly, is on the right direction, in ensuring them to be fully recovered, and more importantly, preventing the morbidity and mortality from the disease. However, sometimes, due to the stretched capability, these criteria were treated flexibly, as the decision for hospitalization depends on the judgments of the Family Medicine Specialist onsite. The finding recommends that the CAC team should be more cautious by lowering their decision threshold for hospital admission, for these high-risk group patients.

Understanding the types of patients who are most at risk for hospitalization is vital for a number of reasons. It helps in making triage decisions. It also could help inform policymakers about highest risk populations, who may require particular protection in policy determinations. Lastly, it helps epidemiologists to properly plan about the likely need for hospital beds and staffing needs in a region given its demographic characteristics (Petrilli, C.M. et al., 2020).

\section{Study Limitations}

The current study has some limitation. First, the data were derived from a single CAC in a state in Malaysia and may not represent the national population. However, this is the first study done in this location and it is believe it provides unique insights into the disease. 
Despite the limitation, the study results are consistent with previous studies of COVID-19 cases, both globally and nationally. Secondly, the variables studied were limited, because the source was secondary data that were already available in the CAC settings. One recommendation for future studies is to include more variables in the study, collected via constructed questionnaires or interviews.

\section{Conclusion}

Among the home quarantined COVID-19 patients, some of them might require hospitalization later due to disease progression or worsening conditions, especially the elderly patients. Thus, during the first contact, the CAC team should assess them properly, and given priority for hospital admission to these cases instead of giving the home quarantine order, as they are more vulnerable to severe disease and progression when infected with COVID-19.

\section{Acknowledgements}

We would like to thank the Director General of Health Malaysia for permission of the research. We also would like to thank the Melaka State Health Office and Melaka Tengah District Health Office for their cooperation and support for this study. Our deepest gratefulness for those assisted both directly and indirectly in this study. This study is not funded by any organization.

\section{Conflicts of Interest}

This research has no conflicts of interests.

\section{Funding Statement}

Nil.

\section{References}

Ahmad B.Z., Marleena B.A., Zulraini J., Rusdi A.R., Ismail, A.. (2021). Factors Associated with COVID-19 Infection in Melaka: One Year Experience from March 2020 till March 2021. BEJ, 2(S1), November 2021. https://jurcon.ums.edu.my/ojums/index.php/bej/article/view/3591

Ahmad, N., Mohd Ali, N.F., Mohamed Nawi, A., Hassan, M.R., Noor Aizuddin, A., Hod, R., Daud, F., Salleh, S.A., Periyasamy, P., Abdul, G.A.H., Kori, N. (2021). Clinical Characteristics of Patients with Coronavirus Disease 2019 (COVID-19) in a Teaching Hospital in Malaysia. $J$. Infect. Dev. Ctries., 15(8), 1059-1065. https://doi.org/10.3855/jidc.13232

Charan, J., Biswas, T. (2013). How to Calculate Sample Size for Different Study Designs in Medical Research? Indian J. Psychol. Med., 35(2), 121-126. https://doi.org/10.4103/0253-7176.116232

COVIDNOW. (2021). COVIDNOW in Malaysia. https://covidnow.moh.gov.my

Gottlieb, M., Sansom, S., Frankenberger, C., Ward, E., Bala, H. (2020). Clinical Course and Factors Associated With Hospitalization and Critical Illness Among COVID-19 Patients in Chicago, Illinois. Acad. Emerg. Med., 27(10), 963-973. https://doi.org/10.1111/acem.14104

Hasani, W.S.R., Ganapathy, S.S., Lin, C.Z., Mat Rifin, H., Bahari, M.N., Ghazali, M.H., Lodz, N.A., Ramli, M.H.T., Majid, N.L.A., Ling, M.Y.J., Yusoff, M.F.M., Ahmad, N.A., Suleiman, A., Yusoff, A.F., Balan, V., Ngadiman, S. (2021). Comorbidities and Clinical Features Related to Severe Outcomes Among COVID-19 Cases in Selangor, Malaysia. Western Pac. Surveill. Response J., 12(1), 46-52. https://doi.org/10.5365/wpsar.2020.11.3.007

Intan A.M.D., Hazlinda H., Azlina A., Rusdi A.R. (2021). Brought in Death (BID) COVID-19 Cases in Melaka from January to August 2021: A Descriptive Study. BEJ, 2(S1), November 2021. https://jurcon.ums.edu.my/ojums/index.php/bej/article/view/3591 
Ko, J.Y., Danielson, M.L., Town, M., Derado, G., Greenlund, K.J., Kirley, P.D., Alden, N.B., Yousey, H.K, Anderson, E.J., Ryan, P.A., Kim, S., Lynfield, R., Torres, S.M., Barney, G.R., Bennett, N.M., Sutton, M., Talbot, H.K., Hill, M., Hall, A.J., Fry, A.M., Garg, S., Kim, L. (2020). Risk Factors for COVID-19-Associated Hospitalization: COVID-19-Associated Hospitalization Surveillance Network and Behavioral Risk Factor Surveillance System. Clin. Infect. Dis., 72(11), e695-e703. https://doi.org/10.1093/cid/ciaa1419

Malaysia Ministry of Health (MOH). (2021). Guidelines on Home Monitoring and Clinical Protocol at Primary Care for Category 1 and Category 2 (mild) Confirmed COVID-19 Cases. Family Health Development Division. 24 ${ }^{\text {th }}$ March 2021. https://covid-19.moh.gov.my/garispanduan/garis-panduan-

kkm/ANNEX 2m Guidelines on Home Monitoring and Clinical Protocol at Primary Car e_for_Cat_1_and_2_Mild_Confirmed_COVID-19_Cases_02122021.pdf

Mendy, A., Apewokin, S., Wells, A. A., Morrow, A. L. (2020). Factors Associated with Hospitalization and Disease Severity in a Racially and Ethnically Diverse Population of COVID-19 Patients. medRxiv., $\quad$ medRxiv2020.06.25.20137323. http://dx.doi.org/10.1101/2020.06.25.20137323

Petrilli, C.M., Jones, S.A., Yang, J., Rajagopalan, H., O’Donnell, L., Chernyak, Y., Tobin, K.A., Cerfolio, R.J., Francois, F., Horwitz, L. (2020). Factors Associated with Hospital Admission and Critical Illness among 5279 People with Coronavirus Disease 2019 in New York City: Prospective Cohort Study., BMJ, 369, m1966 (1-15). https://doi.org/10.1136/bmj.m1966

Telle, K.E., Grosland, M., Helgeland, J., Haberg, S.E. (2021). Factors Associated with Hospitalization, Invasive Mechanical Ventilation Treatment and Death among all Confirmed COVID-19 Cases in Norway: Prospective Cohort Study. Scand. J. Public Health., 49(1), 41-47. https://doi.org/10.1177/1403494820985172

World Health Organization (WHO). (2021). WHO Coronavirus (COVID-19) Dashboard. Accessible at https://covid19.who.int. 